\title{
CLINICAL OUTCOME OF CHEWING GUM ON BOWEL MOTILITY AMONG PATIENTS UNDERGOING ABDOMINAL SURGERY
}

\section{Amit Karad ${ }^{1}$, Baviskar PK ${ }^{2}$, Khilchand Bhangale ${ }^{3}$, Amol Chaudhary ${ }^{4}$}

${ }^{1}$ Resident ${ }^{1},{ }^{2}$ Professor, ${ }^{3}$ Assistant Professor, ${ }^{4}$ Senior Resident, Department of Surgery, Rural Medical College, Pravara Institute of Medical Sciences (Deemed University), Loni, Maharashtra, India

\section{ABSTRACT}

Introduction: Postoperative paralytic ileus is one of the commonest causes of morbidity in abdominal surgeries. The aim of the present study was to evaluate efficacy of chewing gum in on bowel motility among patients who have undergone abdominal surgery. Methods: The details of patients along with diagnosis, co-morbidities, duration of anesthesia \& surgery and post-operative stay were recorded. Patients that received chewing gum in addition to standard postoperative care were grouped as cases while those that received standard postoperative care were grouped as controls. The patients were observed for Peristaltic Sounds, Flatus passed, Stool Passed, return of appetite and time was recorded. Results: The study was conducted with 200 patients of which 100 each were grouped as cases and controls. Majority of the patients in Cases Group were in the age group of 40-50 years (42\%). The mean age of the patients was $47.3 \pm 12.97$ years. 7 (23.3\%) patients in Cases Group had hypertension while 5 (16.7\%) patients had diabetes mellitus. $8(26.8 \%)$ patients in Control Group had hypertension while $4(13.4 \%)$ patients had diabetes mellitus. 47 (47\%) patients in Cases Group had enterocolon diseases while $43(43 \%)$ and 10 (10\%) patients had hepatobiliary and pancreatic diseases respectively. 46 (46\%) patients in Control Group had enterocolon diseases while 45 (45\%) and 9 (9\%) patients had hepatobiliary and pancreatic diseases respectively. There was no statistical significance on comparison between the groups with respect to age, sex, co-morbidities and diagnosis. The mean duration of induction of anesthesia was $27.08 \pm 0.89$ minutes and $28.16 \pm 1.14$ minutes in Cases and Control Group respectively. The mean duration of surgery was $2.67 \pm 0.21$ hours and $2.44 \pm 0.19$ hours in Cases and Control Group respectively. The mean duration of return of Bowel Sound was significantly lesser in Cases Group as compared to Control Group ( $9.9 \pm 1.37$ vs. $36.1 \pm 6.72$ hours). The mean duration of first passage of flatus was significantly lesser in Cases Group as compared to Control Group ( $14.8 \pm 2.13$ vs. $81.1 \pm 5.47$ hours). The mean duration of time to first faeces was significantly lesser in Cases Group as compared to Control Group (36.1 \pm 7.28 vs. 107.6 \pm 6.87 hours). The mean duration of return of appetite was significantly lesser in Cases Group as compared to Control Group (19.3 \pm 2.13 vs. $87.6 \pm 5.47$ hours). The duration of post-operative hospital stay was significantly lesser in Cases Group as compared to Control Group ( $72.1 \pm 7.28$ vs. $155.6 \pm 6.87$ hours) Conclusion: Gum chewing in patients undergoing abdominal surgery can be an effective intervention to facilitate the passage of flatus and feces, shorten the time to dietary intake, and shorten the length of hospital stay by promoting bowel motility.

Key words: Abdominal surgery, Bowel motility, Chewing gum

\section{INTRODUCTION}

Postoperative ileus is a one of the important and consistent effect of major abdominal surgery. While the pathophysiology is multifactorial and not well understood, it leads to significant morbidity, and is a frequently leads to gastroenterological referral. It is defined as transient inhibition of normal gastrointestinal motility in the postoperative setting, typically lasting 35 days after surgery [1].

$40 \%$ of patients undergoing laparotomy are met with postoperative ileus [2]. It is characterized by abdominal

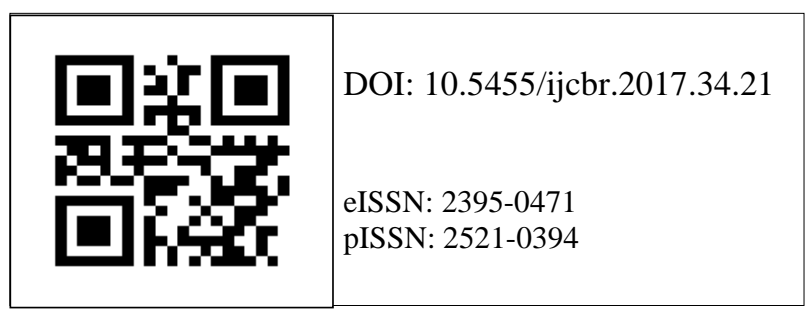

distension, lack of bowel sounds, and lack of passage of flatus or stool, worsened by postoperative pain, nausea and vomiting, delay in resuming enteral nutrition, and prolonged hospitalization. Other postoperative complications include deconditioning, malnutrition, increased risk of nosocomial infections and pulmonary complications, decreased patient satisfaction and increased health care costs $[2,3]$.

In India, 60 to $70 \%$ of patients with major abdominal surgery develop complication due to postoperative ileus which leads to discomfort, prolonged hospital stay and economic burden [4].

Postoperative ileus is managed by gastric decompression through Ryle's tube, keeping the patient nil per orally, intravenous fluid supplementation till ileus resolves, and patient passes flatus [5].

There are many nonpharmacologic treatment such as early enteral nutrition, early mobilization, laparoscopic surgery, psychological preoperative preparation among

Correspondence: Dr. Baviskar PK, Professor, Department of Surgery, Rural Medical College, Pravara Institute of Medical Sciences (Deemed University), Loni, Maharashtra, India. Email: surgery@pmtpims.org 
them the use of chewing gum also has emerged as a new, simple, readily available and cost effective modality for decreasing POI. It acts by stimulating intestinal motility through cephalic vagal reflex and by increasing the production of gastrointestinal hormones associated with bowel motility that result in early return of bowel sounds, passage of flatus and return of appetite. Hence the researcher has taken up the study to evaluate the efficacy of chewing gum on bowel motility after abdominal surgery [6].

Hence the present study was done at our tertiary care centre to evaluate the efficacy of chewing gum on bowel motility among patients who have undergone abdominal surgery.

Aim \& Objective: To evaluate the efficacy of chewing gum on bowel motility among patients who have undergone abdominal surgery. MATERIALS AND METHODS

Study design: Non randomized clinical trial

Ethics approval: The study was conducted after approval of ethics committee approval and informed consent was taken from the all participants.

Study location: Department of Surgery, Pravara Rural Hospital, Loni,

Study period: September 2015 to December 2017.

Inclusion criteria: Patients who had undergone elective or Emergency (Open Abdominal surgery) for Infective, Non Infective, Malignant, Non Malignant, Traumatic causes or Retro peritoneal Explorations, which has lead to parasitic ileus, received/ not received chewing gum 8 hours post-Surgery done under GA or 6 hours in case of Surgeries done under RA.

Exclusion criteria: Patients who were pregnant or lactating, who did not develop paralytic ileus post operatively, who were critically ill with multi-organ failure were excluded from the study.

Sample size: Considering a confidence level of $95 \%$ and confidence interval of 7 the number of patients in our study to achieve statistical significance is 196 . This was calculated by Survey System. Hence a sample size of 200 was considered adequate for our study.

Grouping: Divided into 2 grouping based on the received chewing gum or not in addition to standard postoperative care.

\section{Methodology}

The details of patients along with diagnosis, comorbidities, duration of anesthesia \& surgery and postoperative stay were recorded. According to whether the patient received chewing gum, the patients were grouped as Cases (that received chewing gum in addition to standard postoperative care) and Control (that received standard postoperative care). The patients were observed for Peristaltic Sounds, Flatus passed, Stool Passed, return of appetite and time was recorded.

\section{RESULTS}

A hospital based comparative study was conducted with 200 patients to evaluate the efficacy of chewing gum on bowel motility among patients who have undergone abdominal surgery. Each group consisted of 100 patients.

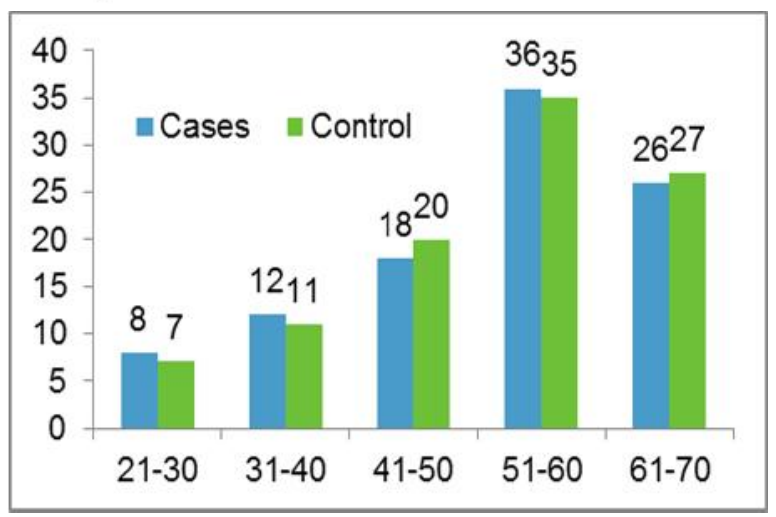

Figure 1: Distribution of patients according to Age Majority of the patients in Cases Group were in the age group of $40-50$ years (42\%) followed by $51-71$ years (34\%), $25-40$ years $(16 \%)$ and $21-25$ years $(8 \%)$. The mean age of the patients was $47.3 \pm 12.97$ years.

Majority of the patients in Control Group were in the age group of $40-50$ years (45\%) followed by $51-71$ years (33\%), $25-40$ years (15\%) and $21-25$ years $(7 \%)$. The mean age of the patients was $47.0 \pm 12.35$ years. There was no significant difference between the groups as per Student t-test $(p>0.05)$.

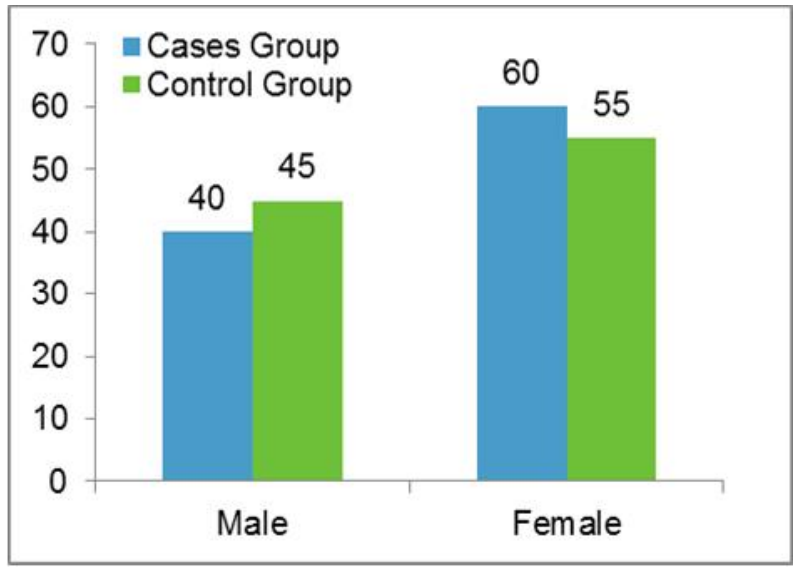

Figure 2: Distribution of patients according to Sex

There were 40 (40\%) male and 60 (60\%) female patients in Cases Group while there was 45 (45\%) male and 55 (55\%) female patients in Control Group. There was no significant difference between the groups as per Fisher test ( $p>0.05)$.

7 (23.3\%) patients in Cases Group had hypertension while $5(16.7 \%)$ patients had diabetes mellitus. 8 (26.8\%) patients in Control Group had hypertension while 4 (13.4\%) patients had diabetes mellitus. There was no significant difference between the groups as per Chi-Square test $(p>0.05)$. 


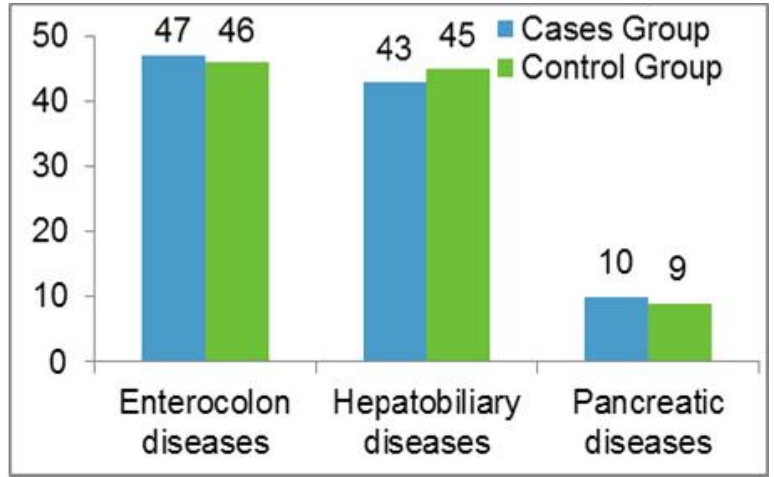

Figure 3: Distribution of patients according to Diagnosis

47 (47\%) patients in Cases Group had enterocolon diseases while 43 (43\%) and $10(10 \%)$ patients had hepatobiliary and pancreatic diseases respectively. 46 (46\%) patients in Control Group had enterocolon diseases while $45(45 \%)$ and $9(9 \%)$ patients had hepatobiliary and pancreatic diseases respectively. There was no significant difference between the groups as per Chi-Square test ( $p>0.05)$.

Table 1: Effect of chewing gum on Bowel activity

\begin{tabular}{|c|c|c|}
\hline & Control & Case \\
\hline $\begin{array}{l}\text { Duration of induction of } \\
\text { Anaesthesia (minutes) }\end{array}$ & $28.16 \pm 1.14$ & $27.08 \pm 0.89$ \\
\hline $\begin{array}{l}\text { Duration of surgery } \\
\text { (hours) }\end{array}$ & $2.44 \pm 0.19$ & $2.67 \pm 0.21$ \\
\hline $\begin{array}{l}\text { Return of bowel sound } \\
\text { (hours) }\end{array}$ & $36.1 \pm 6.72$ & $9.9 \pm 1.37 *$ \\
\hline $\begin{array}{l}\text { First passage of flatus } \\
\text { (hours) }\end{array}$ & $81.1 \pm 5.47$ & $14.8 \pm 2.13^{*}$ \\
\hline First faeces & $107.6 \pm 6.87$ & $36.1 \pm 7.28^{*}$ \\
\hline $\begin{array}{l}\text { Return of appetite } \\
\text { (hours) }\end{array}$ & $87.6 \pm 5.47$ & $19.3 \pm 2.13^{*}$ \\
\hline $\begin{array}{l}\text { Duration of postopera- } \\
\text { tive hospital stay (hours) }\end{array}$ & $155.6 \pm 6.87$ & $72.1 \pm 7.28 *$ \\
\hline
\end{tabular}

*Significant

\section{DISCUSSION}

In the present study, majority of the patients in Cases Group were in the age group of $40-50$ years $(42 \%)$ followed by $51-71$ years (34\%), $25-40$ years (16\%) and $21-$ 25 years $(8 \%)$. The mean age of the patients was $47.3 \pm 12.97$ years. Majority of the patients in Control Group were in the age group of $40-50$ years (45\%) followed by $51-71$ years (33\%), $25-40$ years (15\%) and 21 25 years $(7 \%)$. The mean age of the patients was $47.0 \pm 12.35$ years. There was no significant difference between the groups as per Student t-test $(p>0.05)$.

There were 40 (40\%) male and 60 (60\%) female patients in Cases Group while there was 45 (45\%) male and 55 (55\%) female patients in Control Group. There was no significant difference between the groups as per Fisher test ( $p>0.05$ ).

Neena et $\mathrm{al}^{6}$ in a study evaluating the efficacy of chewing gum on bowel motility among patients who had undergone abdominal surgery found age were in the range of 21 to 77 years with mean age $43.9 \pm 12.53$ years in the experimental group compared to the control group that was in range of 22- 65 years with mean age of $43.57 \pm 13.8$ years. Half of the subjects $(53.4 \%)$ were in the age group of $36-55$ years in the experimental group and less than half $(46.6 \%)$ were in the age group of 36-55years in control group. As per gender, $18(60 \%)$ and $16(53.3 \%)$ of the subjects were female in the experimental and the control group respectively.

In our study, 7 (23.3\%) patients in Cases Group had hypertension while $5(16.7 \%)$ patients had diabetes mellitus. 8 (26.8\%) patients in Control Group had hypertension while $4(13.4 \%)$ patients had diabetes mellitus. There was no significant difference between the groups as per Chi-Square test ( $p>0.05$ ).

Neena et al [6] found $6(20 \%)$ and $9(30 \%)$ of subjects had comorbidities (Hypertension, Tuberculosis, diabetes) in the experimental group and the control group respectively. It showed homogeneity of subjects in the control and the experimental groups with reference to their previous history of abdominal surgery and comorbidities.

In the present study, 47 (47\%) patients in Cases Group had enterocolon diseases while 43 (43\%) and 10 (10\%) patients had hepatobiliary and pancreatic diseases respectively. 46 (46\%) patients in Control Group had enterocolon diseases while $45(45 \%)$ and $9(9 \%)$ patients had hepatobiliary and pancreatic diseases respectively. There was no significant difference between the groups as per Chi-Square test ( $p>0.05)$.

Neena et al [6] in a study evaluating the efficacy of chewing gum on bowel motility among patients who have undergone abdominal surgery reported on the basis of the diagnosis $14(46.7 \%)$ and $13(43.3 \%)$ subjects had hepatobiliary diseases in the experimental and control group respectively. Only $3(10 \%)$ subjects from both the groups had pancreatic disease and 13(43.3\%) and $14(46.7 \%)$ subjects had enterocolon diseases in the experimental and the control group respectively. Both the groups are comparable as per $c 2$ test $(p>0.05)$.

The mean duration of induction of anesthesia in our study was $27.08 \pm 0.89$ minutes and $28.16 \pm 1.14$ minutes in Cases and Control Group respectively. The difference between groups was statistically not significant as per Student $t$-test $(p>0.05)$. The mean duration of surgery was 2.67 \pm 0.21 hours and $2.44 \pm 0.19$ hours in Cases and Control Group respectively. The difference between groups was statistically not significant as per Student ttest $(p>0.05)$.

Neena et al [6] found mean duration of induction of anesthesia in minutes was $27 \pm 7.7$ minutes and $28 \pm 8.4$ minutes in the experimental and the control group respectively and mean duration of surgery was $2.68 \pm$ 1.74 hours and $2.44 \pm 0.820$ hours in the experimental and the control group respectively. Both the groups were homogenous as per $t$ test $(p>0.05)$. 
It was observed in our study that the mean duration of return of Bowel Sound was significantly lesser in Cases

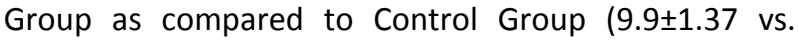
$36.1 \pm 6.72$ hours). The difference between groups was statistically significant as per Student t-test $(\mathbf{p}<0.05)$.

Neena et al [6] found return of bowel sounds before 24 hours were significantly in higher percentage in the experimental group $27(90 \%)$ as compared to the control group $19(63.3 \%)$ as per $c 2$ test $(p<0.05)$.

Craciunas L et al [7] in a meta-analysis on Chewing gum in preventing postoperative ileus in women undergoing caesarean section reported time to first bowel sounds in the chewing gum group was significantly less than that in the control group.

It was observed in our study that the mean duration of first passage of flatus was significantly lesser in Cases Group as compared to Control Group (14.8 \pm 2.13 vs. $81.1 \pm 5.47$ hours). The difference between groups was statistically significant as per Student t-test $(\mathbf{p}<0.05)$.

Neena et al[6] found passage of flatus before 60 hours was significantly higher percentage in the experimental group (66.7\%) as compared to the control group $(23.3 \%)$ as per $c 2$ test $(p<0.05)$.

The mean duration of time to first faeces in our study was significantly lesser in Cases Group as compared to Control Group (36.1 \pm 7.28 vs. $107.6 \pm 6.87$ hours). The difference between groups was statistically significant as per Student t-test $(\mathbf{p}<\mathbf{0 . 0 5})$.

Craciunas $L$ et al[7] in a meta-analysis on Chewing gum in preventing postoperative ileus in women undergoing caesarean section reported compared with the control group, the chewing gum group was associated with a significantly shorter time to first defecation.

Rajakumar $V$ et al [8] in a study on Effectiveness of chewing gum in increasing bowel motility found Mean difference of peristaltic sound in experimental and control group was 10.267 and the' $t$ ' test value was 7.93 , mean difference of passing of gas in experimental and control group was 10.67 and ' $t$ ' test value was 7.697, mean difference of defecation in experimental and control group was 17.233 and ' $t$ ' test value was 7.572 . All the ' $t$ ' test values were significant.

Quah HM et al [9] in a study on chewing gum helps to reduce the onset of postoperative paralytic ileus after the open colectomy for the left sided colon and rectal cancer showed that in control group patients passed flatus in the mean of 2.7 days and defecation by 3.9 days. In the experimental group it took 2.4 days for passing flatus and 3.2 days for defecation.

Schuster $\mathrm{R}$ et al [10] study on chewing gum reducing postoperative paralytic ileus after elective open sigmoid colectomy reported Experimental group patients chewed the sugar free chewing gum three times per day for one hour each time until getting discharge from the hospital. The passage of flatus commenced on 65.4 hours in the experimental group and 80.2 hours in control group. The first peristaltic sounds heard at 63.2 hours in experimental group and 89.4hours in control group. Feeling of hunger occurred in 63.5 hours in experimental group and 72.8 hours in control group. It showed that chewing gum therapy was helpful for the earlier return of the bowel function and helps to reduce the onset of paralytic ileus.

Hong J et a. [11] in a study on Effects of Chewing Gum on Recovery of Bowel Motility after Laparoscopic Colorectal Surgery found the time to the first passage of flatus was shorter in the gum chewing experimental group than in the non-gum chewing control group, the time to the first passage of flatus was $2.96 \pm 1.25$ days in the experimental group and $5.37 \pm 1.23$ days in the control group; the difference in these values was statistically significant $(t=$ 7.716, $\mathrm{p}<.001$ ).

It was observed in our study that the mean duration of return of appetite was significantly lesser in Cases Group as compared to Control Group (19.3 \pm 2.13 vs. $87.6 \pm 5.47$ hours). The difference between groups was statistically significant as per Student t-test $(\mathbf{p}<\mathbf{0 . 0 5})$.

Neena et al [6] found return of appetite before 60 hours was significantly higher percentage in the experimental group (56.7\%) as compared to the control group (13.3\%) as per $c 2$ test $(p<0.05)$.

Hong $J$ et al [11] in a study on Effects of Chewing Gum on Recovery of Bowel Motility after Laparoscopic Colorectal Surgery found the time to the first meal (including beverage) was shorter in the experimental group than in the control group was verified by using the t-test, the time to sipping water was found to be $4.4 \pm 2.04$ days in the experimental group and $5.59 \pm 1.24$ days in the control group $(\mathrm{t}=$ $2.658, p=.010$ ) and time to liquid diet intake was found to be $5.25 \pm 0.91$ days in the experimental group and $6.46 \pm 1.26$ days in the control group; the differences in these values were found to be statistically significant $(t=4.404, p<.001)$.

The duration of post-operative hospital stay in the present study was significantly lesser in Cases Group as compared to Control Group (72.1 1 7.28 vs. $155.6 \pm 6.87$ hours). The difference between groups was statistically significant as per Student t-test $(p<0.05)$.

Neena et al [6] found significant difference in the return of first bowel sounds, passage of flatus and return of appetite between the experimental \& the control group. The mean time of return of bowel sounds after surgery was significantly lesser $(21.4 \pm 2.8 \mathrm{hr})$ in the experimental group than in the control group $(23.7 \pm 2.8 \mathrm{hr})$. Similarly the mean time of passage of flatus after surgery was significantly lesser in $(58.2 \pm 9.3 \mathrm{hr})$ in the experimental group than in the control group $(65.6 \pm 6.4 \mathrm{hr})$. The mean time of return of appetite after surgery was significantly lesser $(59.9 \pm 9.8 \mathrm{hr})$ in experimental group than in the control group $(67.2 \pm 7.6 \mathrm{hr})$. 
Andersson $\mathrm{T}$ et al [12] reported there was a numerical difference in mean time to first flatus, first defecation, start of clear fluids, start of liquid diet and length of hospital stay in favour of the intervention group, although not strong enough to be statistically significant.

Hong J et al [11] in a study on Effects of Chewing Gum on Recovery of Bowel Motility after Laparoscopic Colorectal Surgery found the length of postoperative hospital stay was shorter in the experimental group than in the control group, the length of postoperative hospital stay was found to be $11.21 \pm 2.63$ days in the experimental group and $15.15 \pm 7.41$ days in the control group; the difference in these values was statistically significant $(t=2.829, p=.006)$.

Craciunas $L$ et al [7] in a meta-analysis on Chewing gum in preventing postoperative ileus in women undergoing caesarean section found Compared with the control groups, chewing gum was associated with shorter lengths of hospitalization (SMD $0.26 ; 95 \% \mathrm{Cl} 0.76$ to $0.25 ; z=1.00 ; P=0.32 ;$ ), but the difference was not statistically significant.

\section{CONCLUSION}

In conclusion, the study found that gum chewing in patients undergoing abdominal surgery can be an effective intervention to facilitate the passage of flatus and feces, shorten the time to dietary intake, and shorten the length of hospital stay by promoting bowel motility. Suggestion: Chewing gum after major abdominal surgery is a simple and effective method to treat postoperative paralytic ileus. Chewing gum aids in early recovery from postoperative paralytic ileus and is an inexpensive, simple, effective and physiologic measure for promoting the bowel function. Chewing gum should be added as an adjuvant treatment method in postoperative care because it might contribute to increase the early return of gastrointestinal function after major abdominal surgery. Therefore nurses working in postoperative ward should encourage the clients to chew chewing gum after major abdominal surgery.

Conflict of interest : Nil

\section{REFERENCES}

1. Holte K, Kehlet H. Postoperative ileus: progress towards effective management. Drugs 2002;62:260315.
2. Behm B, Stollman N. postoperative ileus: etiologies and interventions. Clinical gastroenterology and hepatology. 2003;1(2):71-80.

3. Moss G, Regal ME, Lichtig LK. Reducing postoperative pain, narcotics, and length of hospitalization. Surgery 1986;90:206-10.

4. Review related to postoperative paralytic ileus [Available from: URL: http:// www.ukessays.com/essays/health/review related-to-postoperativeparalytic-ileus-healthessay.php]. [Accessed on 2013 September 13].

5. Marwah S,Singla S, Tinna P. Role of gum chewing on the duration of postoperative ileus following ileostomy closure done for typhoid ileal perforation. The Saudi journal of gastroenterology. 2012; 18 (2):111-7.

6. Neena VS, Nimarta, Shruti, Rajesh G. Effectiveness of chewing gum on bowel motility among the patients who have undergone Abdominal Surgery. Nursing and Midwifery Research Journal 2013;9(3).

7. Craciunas L, Sajid MS, Ahmed AS. Chewing gum in preventing postoperative ileus in women undergoing caesarean section: a systematic review and meta-analysis of randomised controlled trials. BJOG. 2014;121(7):793-9.

8. Rajakumar V, Praveen. Effectiveness of chewing gum in increasing bowel motility among clients who had undergone major abdominal surgery. Int. J. Nur. Edu. and Research 2014; 2(4): 385-95

9. Quah H, Samad A. Gum chewing and postoperative ileus following open colectomy, Colorectal Diseases. 2006;8(4):64-70

10. Schuster R, Grewal N, Greaney GC, Waxman K. Gum chewing reduces ileus after elective open sigmoid colectomy. Arch Surg 2006;141:174-6.

11. Shang H, Yang Y, Tong X, Zhang L, Fang A, Hong $L$. Gum chewing slightly enhances early recovery from postoperative ileus after cesarean section: results of a prospective, randomized, controlled trial. Am J Perinatol. 2010;27(5):387391.

12. Andersson T, Bjerså K, Falk K, Olsén MF. Effects of chewing gum against postoperative ileus after pancreaticoduodenectomy--a randomized controlled trial. BM C Res Notes. 2015;8:37.

How to Cite this article: Amit Karad, Baviskar PK, Khilchand Bhangale, Amol Chaudhary. Clinical outcome of chewing gum on bowel motility among patients undergoing abdominal surgery. Int. j. clin. biomed. res. 2017;3(4S):96-100 